\title{
Ammonium and potassium in snow around an emperor penguin colony
}

\author{
ANDREW M. RANKIN and ERIC W. WOLFF \\ British Antarctic Survey, Natural Environment Research Council, High Cross, Madingley Road, Cambridge CB3 OET, UK \\ *a.rankin@bas.ac.uk
}

\begin{abstract}
Snow samples taken at various distances from the emperor penguin (Aptenodytes forsteri) colony near Halley station were analysed by ion chromatography. Extremely high ammonium concentrations were encountered at the colony itself, but fell off sharply with distance from the colony, reaching background levels within a few kilometres of the colony. A seasonal effect was also seen, with the highest concentrations found in spring when the colony was at its most active. Levels of potassium and other sea-salt ions were also elevated near the colony. The ratio of sodium to potassium was lower than that found in bulk seawater, and closer to that found in the penguin's food source, indicating that the increased concentrations are due to emissions from the penguins and not merely to the proximity of open seawater to the site. The colony thus has a significant effect on the composition of the nearby snow, but this effect is strongly localised and is not likely to significantly influence snow chemistry at inland ice core drilling sites.
\end{abstract}

Received 26 July 1999, accepted 10 April 2000

Key words: ammonium, Antarctic, emperor penguin, potassium, snow

\section{Introduction}

The principal sources of ammonium supply to the global atmosphere are thought to be biogenic in origin. According to Deneter \& Crutzen (1994), emissions from the decomposition of urea, from soils (particularly fertilized soils), and from biomass burning dominate the continental inputs to the ammonium budget. Marine biogenic inputs are less well quantified, but ammonium emissions estimated from the relationship between dimethyl sulphide, non-sea-salt sulphate and ammonium marine fluxes (Liss \& Galloway 1993, Clarke \& Porter 1993) suggest that the oceans may contribute $7 \mathrm{Tg} \mathrm{N}$ $-\mathrm{NH}_{3} \mathrm{yr}^{-1}$ of a total global budget of $45 \mathrm{Tg} \mathrm{N}-\mathrm{NH}_{3} \mathrm{yr}^{-1}$, although Legrand et al. (1998) obtained a rather lower figure.

In Greenland, the presence of large landmasses at high latitudes gives a predominantly terrestrial source for atmospheric ammonium, with the largest input being from biogenic emissions from soils (Fuhrer et al. 1996). Ammonium in Greenland ice cores has also been used as a tracer of forest fires (Legrand et al. 1992). There is little evidence for a significant marine source.

Antarctica, however, is separated from the other continental masses of the Southern Hemisphere by the Southern Ocean, and, supporting little terrestrial life of its own, is largely isolated from such terrestrial biogenic inputs. The marine source is therefore expected to be the dominant contributor to ammonium found in Antarctic aerosol and snow (Legrand et al. 1998).

Measurements made in the vicinity of a poultry farm (Fowler et al. 1998) show that decomposition of urea in highlyconcentrated regions of biological activity may contribute a significant local source of ammonium to the atmosphere. In coastal Antarctica, such sites are common in the form of bird colonies, and so around them the potential exists for a significant perturbation of the background terrestrial and marine signals.

Ammonium is not the only species that may be affected by the presence of bird colonies. The high salt content of penguin food (which for emperor penguins in the Weddell Sea region is principally Antarctic krill (Euphausia superba Dana), with some Antarctic silverfish (Pleurogramma antarcticum Boulenger) (Klages 1989, Putz 1995)) necessitates efficient removal of ions from the digestive system and bloodstream, and penguins produce urine that is highly concentrated in the sea salt ions (Janes 1997). Nasal salt glands also help in the removal of these ions, and in the vicinity of penguin colonies nasal secretions and urine may between them constitute an important local source of sea salt ions.

Ammonium, potassium and various other chemical species have been measured in aerosol collected at three sites around the French station of Dumont d'Urville, where a large colony of Adélie penguins (Pygoscelis adeliae (Hombron \& Jacquinot)) is present in the summer months (Legrand et al. 1998). The high ammonium concentrations found (relative to other coastal Antarctic stations) were attributed to emissions from guano-enriched soils (as were high oxalate concentrations), whilst high potassium, magnesium, sulphate and calcium levels were attributed to nasal secretions from the penguins. Samples taken from an island a few kilometres from the station, with a smaller population of penguins, were found to have ammonium concentrations around one tenth of those found near the main colony

Where biological activity does exist in Antarctica, therefore, there is potential for a strong, localized perturbation of the 
natural terrestrial and marine signals of various chemical species. This paper focuses on the impact of a large emperor penguin colony on the chemistry of the surrounding snow. The strength of the local input is assessed relative to the dominant marine sources, and the question of whether local ice cores may be used to infer the past activity of colonies is addressed.

\section{Sampling sites and procedures}

\section{Sampling sites}

An emperor penguin colony is situated on fast ice at the edge of the Brunt Ice Shelf, c. $15 \mathrm{~km}$ from Halley station of the British Antarctic Survey. It is estimated to contain about 15000 breeding pairs (Woehler 1993). These begin to arrive in June after the sea ice forms, and after laying, the female returns to sea to feed while the male remains to incubate the single egg. The eggs hatch around the end of August, and the female returns to take over the rearing of the chick while the male goes to sea to feed. After a few more weeks the male returns and the chicks are left alone as both parents go to sea, one or other returning every few days with food for their offspring. The chicks finally leave the colony as the sea ice begins to break up in late December/early January (Stonehouse 1953, Williams 1995).

Snow samples were taken at eight stations: at the colony itself, and at distances of $0.2,0.5,1,2,4,8$, and $16 \mathrm{~km}$ from it. Stations 1 and 2 (at the penguin colony and at $200 \mathrm{~m}$ from it) were situated on sea ice, whilst the remainder were on the ice shelf proper. The three sets of samples were intended to be taken in August (before the chicks had hatched), October and December, but bad weather and unavailability of personnel meant that the first samples were not taken until 8 October, by which time the colony was already busy with young chicks. The sites were flagged and the subsequent sets of samples taken on 13 November and 14 January.

By November the size of the colony site had increased, and the groups of birds were more dispersed so that both stations 1 and 2 could be considered to be in the colony. The snow surface was visibly dirtier than in October.

By mid-January much of the sea ice had broken away from the shelf edge, leaving only $150 \mathrm{~m}$ from the shelfedge with less than 15 adult birds and $c$. 50 chicks remaining on the site. Large tide cracks prevented safe access to the site, so no colony sample was taken and the sample at station 2 was taken at the top of the access ramp to the ice shelf, $c .40 \mathrm{~m}$ from the site of station 2 for the October and November samples.

The samples were taken in a line bearing approximately south-east from the colony. The predominant wind direction at Halley is easterly, with a significant proportion of westerlies also. Winds with a strong northerly or southerly component are rare (König-Langlo et al. 1998).

\section{Sampling procedure}

Four snow samples were taken at each station: two from the surface layers at $0-2 \mathrm{~cm}$ depth, and two from $2-5 \mathrm{~cm}$ depth. Samples were normally taken by walking upwind from the flagged track between the penguin colony and Halley station, and pushing $2 \mathrm{~cm}$ diameter polyethylene sample tubes horizontally into the snow. The surface snow was scraped away with a clean polythene gloved hand to obtain the two lower samples at each site. During the winter sampling, the snow was often too hard to sample in this way, particularly for the lower samples, so instead the sample layer was broken up with an ice axe, and the lumps pushed into the sample tube with a clean gloved hand. A procedural blank was also taken at each site by opening a sample tube and pushing it away from the person doing the sampling, as though taking a snow sample.

\section{Analyses}

Samples were analysed for cations and anions using Dionex 2010i and DX500 ion chromatographs. For cations, high concentrations were analysed with a $10 \mu \mathrm{l}$ sample loop using an isocratic pump with $20 \mathrm{mM}$ MSA eluent, CG12 and CS 12 columns and a conductivity detector. For lower concentration samples, a $500 \mu \mathrm{l}$ sample loop was used to provide better sensitivity.

For anions, high concentration samples were analysed with a $25 \mu \mathrm{l}$ sample loop and a gradient separation with sodium hydroxide eluent, AGI 1 and AS 11 columns and a conductivity detector, while, for lower concentration samples, a $300 \mu \mathrm{l}$ injection was used.

The procedural blank sample tubes used in the field were filled with $10 \mathrm{ml}$ of high purity water, allowed to stand overnight and then analysed with the other samples. The blanks obtained were not significantly different to analytical blanks of high purity water that had not gone through this process, and so no corrections were made to the concentrations obtained for the samples. The precision of the ionchromatographic measurements was of the order $5 \%$, rising to somewhat higher uncertainties for ammonium and potassium levels below $10 \mu \mathrm{g} \mathrm{kg}^{-1}(10 \mathrm{ppb})$.

\section{Results}

\section{Ammonium}

Ammonium concentrations on the three different sampling occasions are shown in Fig. 1. In October the concentration of ammonium at the colony is considerably elevated above background levels, but at only $500 \mathrm{~m}$ from the colony, the concentration has returned almost to the background level of around $3 \mathrm{ppb}$. By November the concentrations at the colony have risen to values many orders of magnitude above the background, but again by station 3 the levels are back down to 

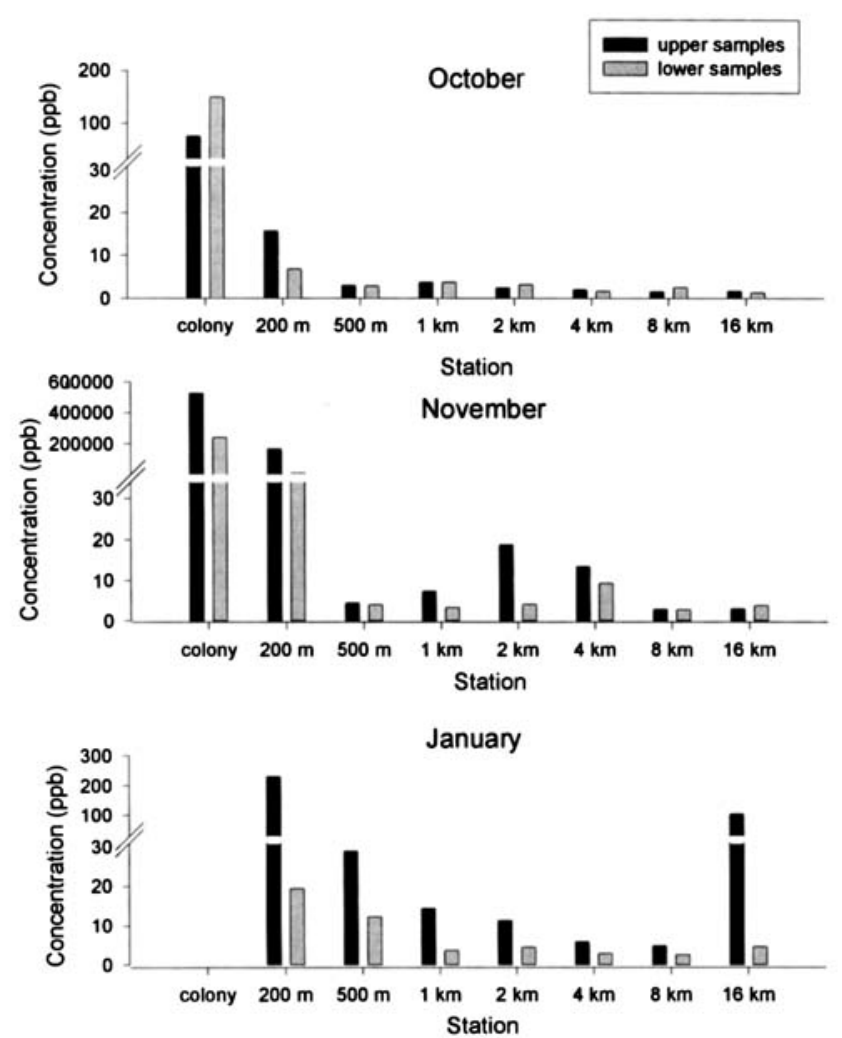

Fig. 1. Concentration of ammonium in snow samples at various distances from the penguin colony on three sampling occasions. Note the changes in scale. The high value recorded at $16 \mathrm{~km}$ from the colony in January may reflect contamination from the nearby station.

the background level. The surface sample for station 2 is considerably more contaminated than the lower sample, which may reflect the recent expansion of the colony over the site of this station. In January, no values are available for the colony itself, but concentrations are slightly elevated at stations 2 and 3 , and indeed a downwards gradient with distance from the colony appears to be present even further from the colony.

\section{Potassium and other sea-salt ions}

The concentrations of potassium found in the samples on the three sampling occasions are shown in Fig. 2. In both the November and January samples a downwards gradient with distance from the colony is readily apparent, although the situation is less clear in October. The ratios of potassium to sodium in the samples are given in Fig. 3, and the ratios of sulphate, calcium and magnesium to sodium in Fig. 4.

\section{Discussion}

\section{Ammonium}

The large increase in the ammonium concentrations at the colony between October and November may be attributed to
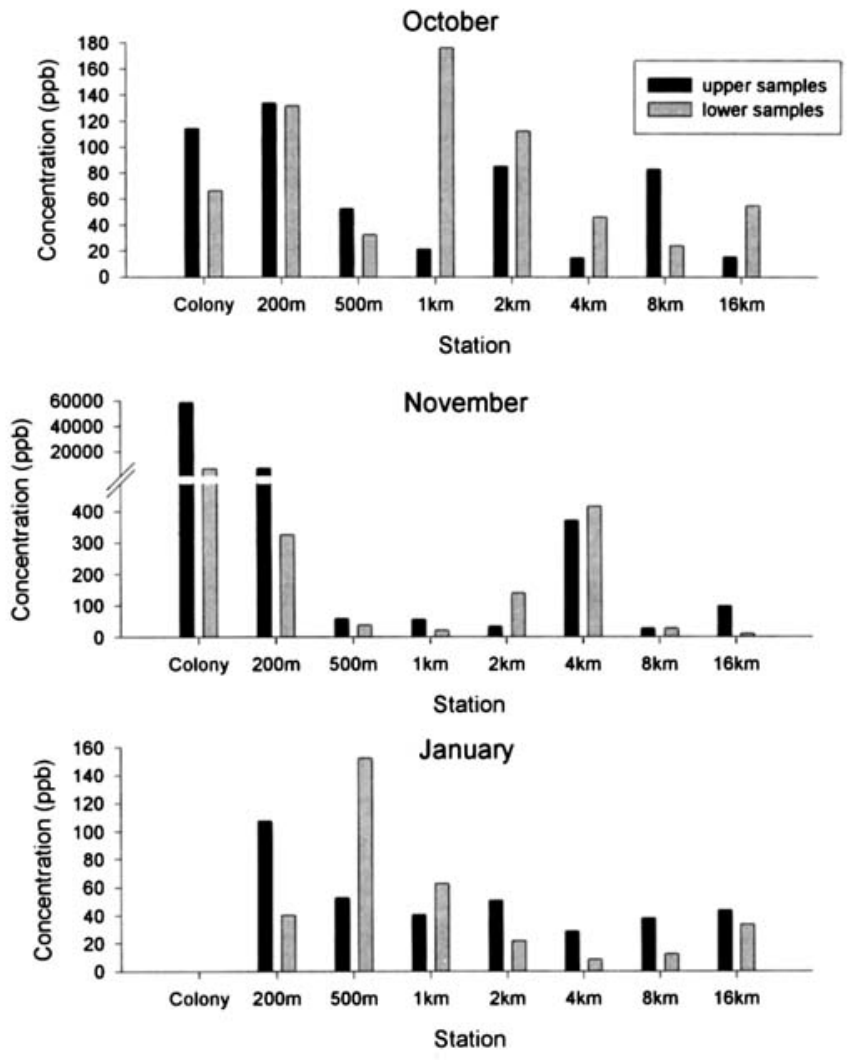

Fig. 2. Concentration of potassium in snow at various distances from the penguin colony on three sampling occasions. Note the change in scale in the November graph.

the increase in the activity of the birds. The male penguins fast during the incubation of the eggs, and even after the eggs have hatched feeding activity is slow for a few weeks, as the parents must travel over a considerable distance of sea ice to reach their feeding grounds. It is not until the sea ice begins to recede that the parents are able to bring food for their offspring every few days. Production of guano, and hence ammonium, is therefore likely to be very much increased as spring proceeds.

Time-series of ammonium concentrations in aerosol collected at various coastal Antarctic sites (Legrand et al. 1998) show that a strong peak is seen annually shortly after midsummer. If, as is surmised, the largest input of ammonium to the continent is from marine biota, the concentration in aerosol and surface snow layers would be expected to increase in summer when primary production is highest, and would also be expected to decrease with distance from the sea. This is consistent with the pattern seen in the January samples, which have generally higher concentrations at some distance from the colony than the corresponding samples in October and November, and also show a decrease with distance from the open sea, which by January is very close to the colony.

In October, the ammonium concentrations found in the snow at distances greater than $1 \mathrm{~km}$ from the colony are typically $2-3 \mathrm{ppb}$, and rather higher by the late spring/early summer. These values compare well with an average value of 

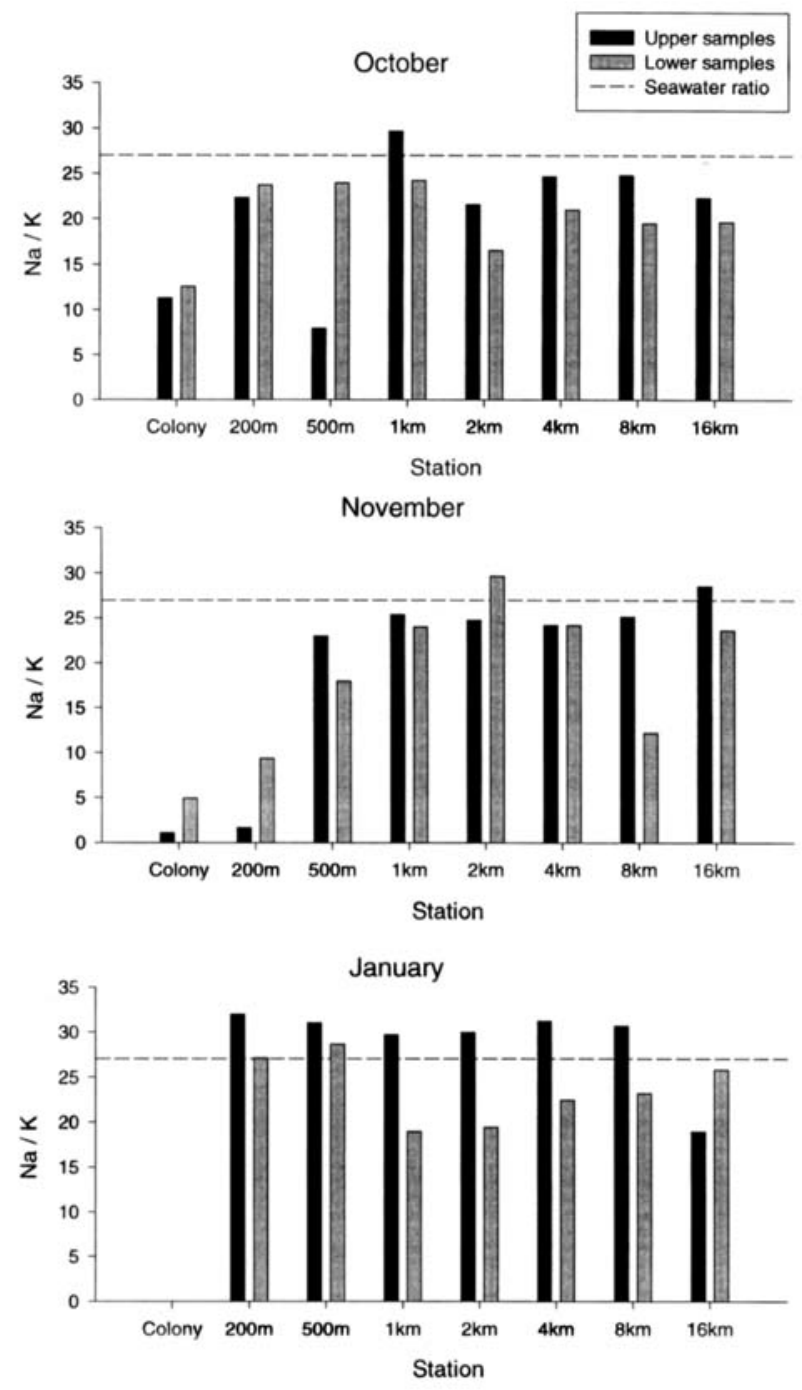

Fig. 3. Sodium / potassium weight ratios in snow at various distances from the penguin colony on three sampling occasions.

$2.4 \mathrm{ppb}$ found in a Berkner Island firn core, and $7.5 \mathrm{ppb}$ in fresh surface snow at Neumayer station, and show that the effect of the penguins is indeed very localized. A firn core at the South Pole gave an average concentration of $1.1 \mathrm{ppb}$ (Legrand et al. 1998).

It should be noted that the particular circumstances of the colony at Halley may give rise to less ammonium being transported inland than at other sites. As the colony is situated on ice, the waste the penguins produce can be absorbed and frozen into the ice; where colonies are situated on bare rock or soil the ammonium may be more easily entrained into the atmosphere. Although emperor penguins breed almost exclusively on sea ice, this is rarely the case for the other species of penguin. Also, the prevailing winds at Halley are easterlies, blowing from the colony into the Weddell Sea. The samples were taken in a line bearing approximately south-east from the colony. A stronger effect may well be seen where the prevailing winds blow inland from bird colonies.

Organic acids were not quantified in the samples, owing to
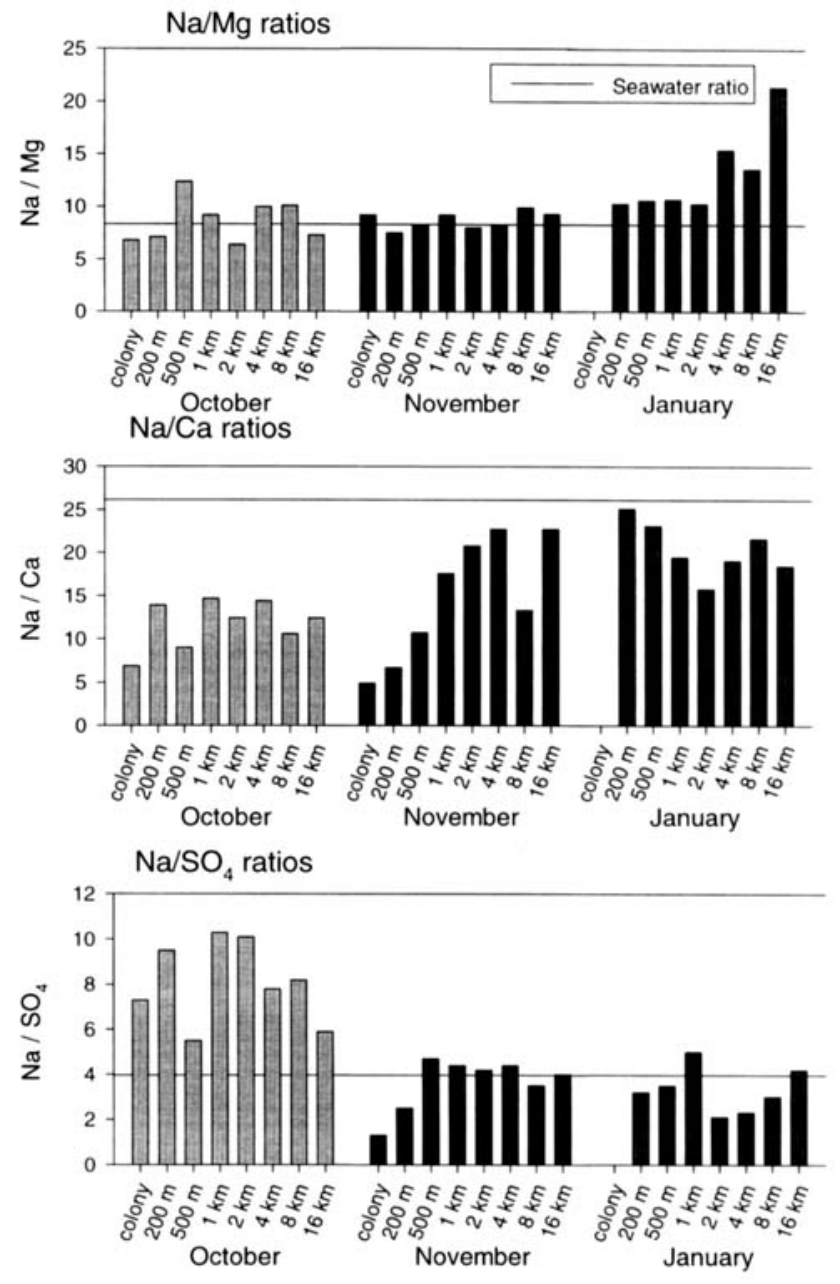

Fig. 4. Weight ratios of sodium to magnesium, calcium and sulphate in snow samples at various distances from the penguin colony on three sampling occasions (averages of two surface and two sub-surface samples).

possible contamination from the plastic sample tubes used. However, the oxalate peak was readily identifiable in many of the chromatograms obtained from samples near the colony, and the height was clearly correlated to the ammonium concentrations encountered in those samples. Whereas ammonium is present both in fresh guano from the birds and as a breakdown product of the urea (Lindeboom 1984), oxalate is only present in very low concentrations in fresh guano (Hutchison 1950). It might be possible to obtain information on the breakdown rate of the urea and the fraction of the ammonium coming from fresh guano by looking at the ratios of ammonium to oxalate found in the samples.

The mobilization processes for the species under consideration must be taken into account when considering transport from the colony. Whereas particulate species require mobilization by wind action, some ammonium may be mobilized as gaseous ammonia and subsequently neutralised into sulphuric acid aerosols derived from oxidation of DMS (Legrand et al. 1998). The transport of ammonium cannot 
therefore be expected to follow the same pattern as other species that are only generated directly as aerosols.

\section{Potassium and other sea-salt ions}

The increased potassium concentrations around the colony in the November and January samples could again be due to emissions from the penguins. However, as the colony is closer to open water than stations further from the colony, there may also be an increased component of sea-salt potassium, particularly in January when the sea ice is breaking up. In order to differentiate between the signal from penguin emissions and the marine signal, it is useful to look at the ratio of sodium to potassium in the samples.

Janes (1997) investigated the ionic composition of the regurgitated food fed to Adélie penguin chicks by their parents, which is also primarily Antarctic krill. The ratio of Na to $\mathrm{K}$ by weight in the samples was $1.56: 1$, compared with the bulk sea water ratio of 27:I. As the total output from the penguins in faeces, urine and nasal salt gland secretions must be equal in ionic composition to their food intake, we would expect signals from penguin emissions to be characterized by a low $\mathrm{Na}: \mathrm{K}$ ratio compared with marine signals.

The ratios of $\mathrm{Na}$ to $\mathrm{K}$ on the three sampling occasions are shown in Fig. 3. It can be seen that in October and November the ratio at the colony is significantly less than the bulk sea water ratio. However, only $500 \mathrm{~m}$ away at station 3 the ratio is closer to 27 , the figure expected from sea-salt aerosol. In January, when almost all the penguins have left the colony, no deviation from the bulk sea water ratio is seen even close to the site of the colony. The increase in potassium at the colony in January cannot therefore be attributed to penguin emissions, but mercly to higher sca-salt loadings due to the proximity of open water to the site.

The concentrations of calcium, magnesium and sulphate in aerosol measured by Legrand et al. (1998) at Dumont d Urville show a similar behaviour to potassium in departing from scasalt ratios close to the penguin colonies. The ratios of sulphate, magnesium and calcium to sodium we found are shown in Fig. 4 (average of all four samples at each site), along with the ratio found in bulk seawater. There is no apparent increase in magnesium relative to sodium at the colony on any of the three occasions. However, Legrand et al. (1998) found a much smaller effect for magnesium than for potassium, calcium or sulphate, and the effect may be too small to be apparent in our results.

The effect is clear for calcium and sulphate in the November samples however, with a strong reduction in ratio near the colony as is seen with potassium. The ratios found for calcium in October are also lower than in November and January even in the stations far from the colony, and all ratios found are rather less than the sea-salt ratio. This suggests there is an additional source for calcium, but what this may be is unclear - although some additional calcium may arrive in Antarctica from terrestrial dust sources, this is unlikely to be sufficient to account for the low ratio seen.

The average $\mathrm{Na}: \mathrm{SO}_{4}$ ratio also changes through the year. This is more likely to be due to fractionation of sea-salt during freezing of sea ice, as described by Wagenbach et al. (1998). This leads to a reduction in sulphate in sea-salt aerosol formed from the sea ice as it freezes, and hence an increase in the sodium to sulphate ratio in the winter months.

\section{Tracers for penguin colony history}

It may be possible to use ice cores drilled in the vicinity of penguin colonies (or colonies of other birds) to investigate the past history of the colonies, at least over short timescales. As the disturbance to the natural background concentrations of ammonium and potassium due to the birds is strong, highly localized and distinguishable from other sources by the concentrations relative to other ions, strong peaks in these species would clearly infer the past presence of birds at the site. However, sites that would be suitable for such investigations are limited. The drill site must have an appropriate snow accumulation rate, and sufficient depth to allow a core covering a reasonable time-series to be obtained, yet be sufficiently close to the colony to pick up the signal. The correction for flow of the ice relative to the colony must also be small. Where colonies are situated on the ice itself this may not be a problem as the colony will move from year to year with the ice (until break-out of the ice front itself occurs), but where a colony site is on land and a glacier or ice sheet nearby is the proposed drilling site, the deeper ice may have originated significantly further away from the colony than that at the surface.

The site of the colony itself at Halley would not be suitable, being situated on sea ice which breaks up every season, but it might be possible to obtain core from the ice shelf nearby which would have been close enough to the colony to pick up the penguins emissions - although, given the accumulation rate of the site, a record of at best a few tens of years might be obtained. There are other sites along the Antarctic Peninsula where although a colony is situated on a rocky site near sea level, there is a nearby glacier that could be drilled.

\section{Conclusions}

Penguins were found to have a marked effect on the composition of the snow surrounding their colonies, with ammonium and potassium in particular having extremely high concentrations in and around the penguin colony studied. However, the effects were both seasonal and localized, the signals from the penguins being almost insignificant relative to other sources at distances of less than one kilometre from the colony.

The results agree well with those from aerosols collected at three sites near penguin colonies around the French station of Dumont d'Urville - in this case chiefly Adélie penguins, although a small colony of cmperor penguins is also present in the winter months. Again, the seasonal cycle of these species 
could be correlated with the activity of the penguins.

\section{Acknowledgements}

We would like to thank the winterers at Halley station for collecting the samples used in this study. Our thanks to John Croxall and Alan Rodger and to the referees Drs D. Wagenbach and L.D. Meeker for their valuable comments on the paper.

\section{References}

Clarke, A.\& Porter, J.N. 1993. Pacific marine aerosol. 2. Equatorial gradient in chlorophyll, ammonium, and excess sulfate during SAGA 3. Journal of Geophysical Research, 98, $16997-17010$.

DENETER, F.J. \& CRUTZEN, P.J 1994. A three-dimensional model of the global ammonia cycle. Journal of Atmospheric Chemistry, 19 $331-369$.

Fowler, D., Pitcairn, C.E.R., Sutton, M.A., Flechard, C., Loubet, B., CoYle, M. \& Munro, R.C. 1998. The mass budget of atmospheric ammonia in woodland within $1 \mathrm{~km}$ of livestock buildings. Environmental Pollution, 102(S1), 343-348.

Fuhrer, K., Neftel, A., Anklin, M., Staffelbach, T. \& Legrand, M. 1996. High-resolution ammonium ice core record covering a complete glacial-interglacial cycle. Journal of Geophysical Research, 101, 4147-4164.

Hutchison, G.E. 1950. Survey of existing knowledge of biogeochemistry. 3. The biogeochemistry of vertebrate excreta. Bulletin of the American Museum of Natural History, 96, 71-94.

JANES, D.N. 1997. Osmoregulation by Adélie penguin chicks on the Antarctic Peninsula. The Auk, 114, 488-495.

KLAGES, N. 1989. Food and feeding ecology of emperor penguins in the eastern Weddell Sea. Polar Biology, 9, 385-390.
Konnig-Langlo, G., King, J.C., Pettré, P. 1998. Climatology of the three coastal Antarctic stations Dumont d'Urville, Neumayer and Halley. Journal of Geophysical Research, 103(D9), 10 935-10946.

Legrand, M., De Angelis, M., St affelbach, T., Neftel, A. \& Stauffer, B. 1992. Large perturbations of ammonium and organic acids content in the Summit Greenland ice cores: fingerprint from forest fires? Geophysical Research Letters, 19, 473-475.

Legrand, M., Ducroz, F., Wagenbach, D., Mulvaney, R. \& Hall, J.S 1998. Ammonium in coastal Antarctic aerosol and snow: role of the polar ocean and penguin emissions. Journal of GeophysicalResearch, 103(D9), II 043-11056.

LiNDEBOOM, H.J. 1984. The nitrogen pathway in a penguin rookery. Ecology, 65, 269-277.

Liss, P.S. \& Galloway, J.N. 1993. Air-sea exchange of sulfur and nitrogen and their interaction in the marine atmosphere. In WOLLAsT, R., MAckenzie, F.T. \& Chou, L., eds. Interactions of C, N, P, and $S$ biogeochemical cycles and global change, Vol. I4. New York Springer-Verlag, 259-281

Putz, K. 1995. The post-moult diet of emperor penguins (Aptenodytes forsteri) in the eastern Weddell Sea, Antaretica. Polar Biology, 15, $457-463$.

STONEHouse, B. 1953. The emperor penguin Aptenodytes forster Gray. I. Breeding behaviour and development. Falklands Islands Dependencies Survey Scientific Reports, No. 6, 33 pp.

Wagenbach, D., Ducroz, F., Mulvaney, R., Keck, L., Minikin, A., Legrand, M., Hall, J.S. \& WolfF, E.W. 1998. Seasalt aerosol in coastal Antarctic regions. Journal of Geophysical Research, 103(D9), $10961-10974$

Williams, T.D. 1995. The penguins. Oxford: Oxford University Press, $295 \mathrm{pp}$.

WOEHLER, E.J. 1993. The distribution and abundance of Antarctic and Subantarctic penguins. Cambridge: SCAR, 76 pp. 